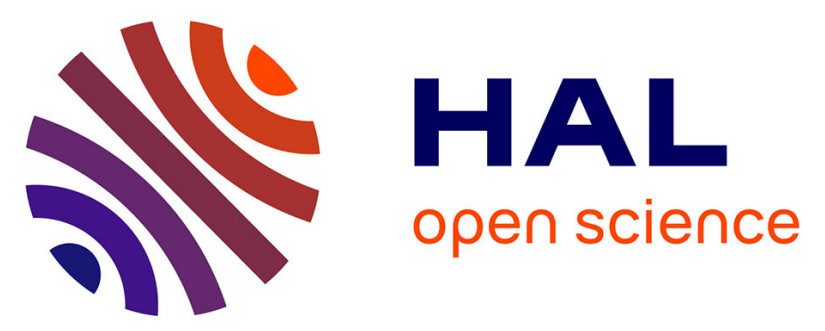

\title{
Macrolide antibiotics removal using a circulating TiO2-coated paper photoreactor: parametric study and hydrodynamic flow characterization
}

Amel Ounnar, Abdelkrim Bouzaza, Lidia Favier, Fatiha Bentahar

\section{- To cite this version:}

Amel Ounnar, Abdelkrim Bouzaza, Lidia Favier, Fatiha Bentahar. Macrolide antibiotics removal using a circulating TiO2-coated paper photoreactor: parametric study and hydrodynamic flow characterization. Water Science and Technology, 2016, 73 (11), pp.2627-2637. 10.2166/wst.2016.096 . hal-01326292

HAL Id: hal-01326292

https://hal-univ-rennes1.archives-ouvertes.fr/hal-01326292

Submitted on 2 Nov 2016

HAL is a multi-disciplinary open access archive for the deposit and dissemination of scientific research documents, whether they are published or not. The documents may come from teaching and research institutions in France or abroad, or from public or private research centers.
L'archive ouverte pluridisciplinaire $\mathbf{H A L}$, est destinée au dépôt et à la diffusion de documents scientifiques de niveau recherche, publiés ou non, émanant des établissements d'enseignement et de recherche français ou étrangers, des laboratoires publics ou privés. 


\title{
Macrolide antibiotics removal using a circulating $\mathrm{TiO}_{2}$-coated paper photoreactor: parametric study and hydrodynamic flow characterization
}

\author{
Amel Ounnar ${ }^{\mathrm{a}, \mathrm{b}, \mathrm{c}^{*}}$, Abdelkrim Bouzaza $^{\mathrm{c}}$, Lidia Favier ${ }^{\mathrm{c}}$ and Fatiha Bentahar ${ }^{\mathrm{b}}$ \\ ${ }^{a}$ Centre de Développement des Energies Renouvelables (CDER), 16340, Algiers, Algeria \\ ${ }^{\mathrm{b}}$ Université des Sciences et de la Technologie Houari Boumediene, Faculté de Génie \\ Mécanique et de Génie des Procédés, Laboratoire des Phénomènes de Transfert, Bab- \\ Ezzouar, 16111 Algiers, Algeria \\ 'Laboratoire «Chimie et Ingénierie des Procédés », Ecole Nationale Supérieure de Chimie de \\ Rennes, CNRS, UMR 6226, 35708 Rennes, France
}

\begin{abstract}
The present work investigates the photocatalytic degradation efficiency of biorecalcitrant macrolide antibiotics in a circulating tubular photoreactor. As target pollutants, spiramycin and tylosin were considered in this study. The photoreactor leads to use an immobilized titanium dioxide on non-woven paper under artificial UV-lamp irradiation. Maximum removal efficiency was achieved at the optimum conditions of natural $\mathrm{pH}$, low pollutant concentration and a $0.35 \mathrm{~L} \mathrm{~min}^{-1}$ flow rate. A Langmuir-Hinshelwood (L-H) model was used to fit experimental results and the model constants were determined. Moreover, the total organic carbon analysis reveals that spiramycin and tylosin mineralization is not complete. In addition, the study of the residence time distribution allowed us to investigate the flow regime of the reactor. Electrical energy consumption for photocatalytic degradation of macrolides using circulating $\mathrm{TiO}_{2}$-coated paper photoreactor (CTCPP) was lower comparing to some reported photoreactors used for the elimination pf pharmaceutic compounds. A repetitive reuse of the immobilized catalyst was also studied in order to check its photoactivity performance.
\end{abstract}

Keywords: flow regime, immobilized catalyst, Langmuir-Hinshelwood model, photocatalytic degradation, photoreactor, waste water.

* Corresponding author. Tel. + 21321901 446, Fax : + 21321901654

E-mail address: amel_ounnar@yahoo.fr/a.ounnar@cder.dz (A.Ounnar) 


\section{INTRODUCTION}

In recent years, recalcitrant organic pollutants (ROPs) in the aquatic environment, such as antibiotics, have attracted an increasing attention due to their nature and impacts on human health and environment (Heberer, 2002; Michael et al., 2013). Their presence and accumulation in natural waters are considered as an emerging pollution problem, leading to the disruption of the ecosystem, the increased malfunction in the reproduction of aquatic species (Heberer, 2002) and possible risks to human health (such as allergies, endocrine disruption and damages to the central nervous system) through drinking water and/or foodchain (Kümmerer, 2000).

Conventional biological treatments have proved to be inefficient for the removal of antibiotics because of their complex molecular structure, high toxicity and poor biodegradability (Kümmerer, 2000). Indeed, these processes were not designed to eliminate such kind of pollutants. Oxidative processes appear to be efficient for the treatment of waste waters containing pharmaceuticals (Doll and Frimmel, 2005). Among them, heterogeneous photocatalysis has emerged as a promising technique for the transformation, deactivation and minimization of persistent organic compounds in water (Doll and Frimmel, 2005). Such process uses semiconductor which is activated under ultraviolet radiation, allowing the generation of highly reactive free $\mathrm{OH}^{\bullet}$ radicals. Among the various solids, titanium dioxide $\mathrm{TiO}_{2}$ is largely employed because of its low cost and photo-stability (Schiavello, 1988).

Several studies have focused on the chemical pathways or degradation kinetics of the process, but there have been only few reports on the design of photocatalytic reactors (Sahle-Demessie et al., 2003). Reactor geometry is also a key factor in liquid-phase photocatalysis which influences the photodegradation efficiency (Paz, 2009). Photoreactor scale-up is a major challenge in photochemical reaction engineering using advanced oxidation process (AOP) technologies for the degradation of ROPs in water (Ghafoori et al., 2014). Using tubular reactor in this work, the main operating parameters such as initial pollutant concentration, $\mathrm{pH}$ and the flow rate can be optimized. An immobilized titanium dioxide $\left(\mathrm{TiO}_{2}\right.$-coated paper) was employed due to the practical interest of reactors operated with immobilized semiconductors (Gholami et al., 2012; Li et al., 2015). Indeed, the use of immobilized catalyst permits to avoid tedious separation step of the particles (Merabet et al., 2009) and its reuse. In addition, residence time distribution (RTD) studies were conducted in order to investigate the effect of the flow rate on pollutant removal efficiency.

Two macrolide antibiotics have been studied in this work: spiramycin (SPM) and tylosin (TYL). Their widespread usage and frequent detection in the aquatic environment highlights the need for their removal. According to recent studies, SPM is one of the most abundant macrolide antibiotic detected in wastewaters (Michael et al., 2013). Its concentration in the effluent of Sewage Treatment Plants has been detected to values up to $0.6 \mathrm{ng} \mathrm{L}{ }^{-1}$. SPM is generally prescribed in the treatment of different types of infections as toxoplasmosis and protozoan infections (Civitareale et al., 2004). TYL is an antibiotic which represents $13 \%$ of the detected drugs. Its detection limit in wastewater is about $0.01 \mathrm{mg} \mathrm{L}^{-1}$ (Huang et al., 2001). TYL is a fermentation derived macrolide antibiotic, which inhibits protein synthesis of specific bacterial species (Elanco, 1982). It is used as feed additive in order to modulate gut microbial flora, thus enhancing the growth rates performances in calves, cattle and poultry. 
The information dealing with the removal of these two antibiotics by heterogeneous photocatalysis is scarce. Up to our knowledge, no works have been reported on the removal of SPM and TYL by using a tubular photoreactor with immobilized $\mathrm{TiO}_{2}$.

The overall aim of this work was to (i) investigate at a pilot scale the effect of some operating parameters on the degradation of target compounds and check the coherence of experimental results with L-H kinetic model; (ii) assess the mineralization of the parent molecules at the end of the reaction process; (iii) investigate the flow regime inside the reactor for different flow rates via residence time distribution (RTD) curves; (iv) evaluate the electrical consumption of the photoreactor system by the determination of electrical energy per order and (v) check the photoactivity performance of the immobilized catalyst over nine cycles.

\section{MATERIALS AND METHODS}

\section{Chemicals}

Spiramycin (purity of 98\%) was kindly offered by Sanofi-Aventis Company for Pharmaceutical Industry (Algeria), and tylosin tartrate was obtained from commercial tylosin, produced by Sinochem Corporation. Their chemical structure and properties were given in Table 1. $\mathrm{KH}_{2} \mathrm{PO}_{4}, \mathrm{~K}_{2} \mathrm{HPO}_{4}, \mathrm{KOH}$ and $\mathrm{HCl}$ used for the preparation of buffer solutions were of reagent grade and were supplied from Biochem, Chemopharma. Analytical-grade organic solvents were used for ultra high performance liquid chromatography analysis. All solutions were prepared with distilled water (resistivity of $2 \mathrm{M} \Omega \mathrm{cm}$ ).

\section{Photocatalyst characteristics}

The used photocatalyst medium was provided by Ahlström Paper Group (referenced as Media 1049). It is a commercial non-woven paper composed of cellulosic fibers coated with a mixture of $\mathrm{TiO}_{2}$ (Millennium PC 500) and $\mathrm{SiO}_{2}$ as an inorganic binder. It has a specific area of $317 \mathrm{~m}^{2} \mathrm{~g}^{-1}$, a pure anatase crystal structure and $1: 1 \quad \mathrm{TiO}_{2} / \mathrm{SiO}_{2}$ mass ratio (from manufacturer data). The quantity of catalyst deposited on the media is equal to $25.5 \mathrm{~g} \mathrm{~m}^{-2}$. Addition of $\mathrm{SiO}_{2}$ can increase the functionality of $\mathrm{TiO}_{2}$. Silica acts as a protector between the fibers and the titanium dioxide. Moreover, silica is transparent to UV, and resists to UV radiation and photocatalysis (Petit et al., 2007, Lhomme et al., 2008).

\section{Photoreactor and procedure}

Photocatalysis experiments were carried out using a continuous tubular photoreactor with a recirculation system (Figure 1). It consists of a stainless-steel column reactor with a cylindrical cross-section $\left(0.62 \times 10^{-2} \mathrm{~m}^{2}\right)$ and an internal volume equal to $1.1 \mathrm{~L}$. The photocatalyst media was placed in filtering arrangement (dead-end filtration), between the stainless-steel support and the column in both top and bottom of the reactor. The two sheets of $\mathrm{TiO}_{2}$-coated paper (corresponding to $0.32 \mathrm{~g}$ of $\mathrm{TiO}_{2}$ ) were renewed for each set of experiments. The solution to be treated was pumped from an open tank of $2 \mathrm{~L}$ capacity under the studied flow rate. An adjustable circulating flow was provided by the mean of a flowmeter and a peristaltic pump. The solution inside the tank was magnetically stirred to keep the solution homogeneous.

A UV-lamp Philips PL-S 9W/10/4P $\left(\lambda_{\max }=365 \mathrm{~nm}\right)$ was used as light source. It is placed in a Pyrex jacket and crosses perpendicularly the middle of the reactor. The lamp was totally 
immersed in the reactor and therefore the maximum light irradiation was achieved. The incident photon flux is equal to $40 \pm 0.2 \mathrm{~W} \mathrm{~m}^{-2}$.

In this work, initial concentration $\left(\mathrm{C}_{0}\right)$ of the substrate was set in the range of $10-80 \mathrm{mg} \mathrm{L}^{-1}$. The fact that this concentration is higher than typical environmental values would not induce any change in the reaction mechanism, or in the reaction products (Santaballa et al., 2006).

Prior the photodegradation tests, the solution is flowing for $30 \mathrm{~min}$ in the dark in order to reach the adsorption/desorption steady state. Then the lamp is switched on to initiate the irradiation and the photocatalysis processes for $300 \mathrm{~min}$. Samples were taken regularly to evaluate the remaining target compound concentration. The $\mathrm{pH}$ and temperature of the solution were also monitored during the runs (WTW inoLab level 1 electrode).

A series of experiments were also conducted in batch mode, in order to investigate the photolytic elimination of the target molecules. No evidence of this phenomenon was observed under the operating conditions.

Moreover, it will be noticed that all experiments were carried out in duplicate and the error is less than $5.0 \%$.

\section{Analysis}

Solution samples were taken over irradiation time and filtered through $0.45 \mu \mathrm{m}$ PTFE Millipore syringe filter prior to analysis. SPM and TYL residual concentrations were monitored by ultra high performance liquid chromatography (UHPLC, Acquity Hclass: Waters), equipped with a photodiode-array detector. Chromatographic separation was performed with a BEH C18 reversed phase column $(100 \mathrm{~mm} \times 2.1 \mathrm{~mm}$ i.d. $\times 1.7 \mu \mathrm{m})$, at $30{ }^{\circ} \mathrm{C}$ and isocratic elution. The mobile phase consisted of $0.1 \%$ of aqueous formic acid in acetonitrile/ultra-pure water $(20: 80 \mathrm{v} / \mathrm{v})$. The injection volume and flow rate were $10 \mu \mathrm{L}$ and $0.4 \mathrm{~mL} \mathrm{m^{-1 }}$, respectively. Analytes were detected at a $\lambda_{\max }$ of 232 (SPM) and $290 \mathrm{~nm}$ (TYL). The total organic carbon (TOC) was measured by using a Shimadzu 1010 Analytical TOC analyzer.

\section{RESULTS AND DISCUSSION}

The degradation kinetics of the target compounds have been analyzed using a pseudo firstorder kinetic model (Gaya and Abdullah, 2008), which can be expressed as:

$$
\operatorname{Ln}\left(\frac{C_{0}}{C}\right)=k_{a p} . t
$$

$\mathrm{C}_{\mathrm{o}}$ and $\mathrm{C}\left(\mathrm{mg} \mathrm{L}^{-1}\right)$ were the concentration of pollutant at $\mathrm{t}=0$ and $\mathrm{t}$ respectively. The apparent rate constant $\left(\mathrm{k}_{\mathrm{ap}}, \mathrm{min}^{-1}\right)$ is given by the slope of the plot of $\ln \left(\mathrm{C}_{\mathrm{o}} / \mathrm{C}\right)$ versus time $(\mathrm{t}, \mathrm{min})$ for the first $30 \mathrm{~min}$ of reaction.

\section{pH effect}

Generally, the degradation rate varies with the solution $\mathrm{pH}$, due to the surface properties of catalyst and ionization ( $\mathrm{pKa}$ ) of organic pollutant. It has been reported that $\mathrm{TiO}_{2}$ at its pure anatase crystalline form, possesses an amphoteric surface and its point of zero charge (PZC) is at $\mathrm{pH} 6.3$ (Parsons, 2004). For the used media, $\mathrm{SiO}_{2}$ binder affects the $\mathrm{PZC}$ of the catalyst. Indeed, it was shown that $\mathrm{pH}$ of the point of zero charge decreases to a value of 3 when the titanium dioxide is supported on silica (Aguedach et al., 2005). Consequently, the surface of the photocatalyst is positively charged at $\mathrm{pH}<3$ and negatively charged at $\mathrm{pH}>3$. 
The experiments were performed over the $\mathrm{pH}$ range $(3-10)$ and all the other parameters were maintained constant. A maximum removal rate of about $80 \%$ was found at natural $\mathrm{pH}$ (corresponding to dissolved pollutant) for both SPM (pH 5.98) and TYL ( $\mathrm{pH} \sim 5.36)$ after 300 min of reaction. It can be observed that $\mathrm{pH}$ highly affects the SPM and TYL degradations which were much faster in acidic media than alkaline solution (Figure 2). In fact, the rate constant $\mathrm{k}_{\mathrm{ap}}$ declines slightly under acidic conditions $(\mathrm{pH} \sim 3)$ for both macrolides, while under alkaline conditions it decreases more strongly for SPM than for TYL.

This difference between the behavior of two antibiotics can be attributed to their pKa (pKaspM $>\mathrm{pKa}_{\mathrm{TYL}}$ ). For the considered pollutants, the high $\mathrm{pKa}$ suggests a high degree of ionization under acidic conditions.

For acidic $\mathrm{pH}$, the adsorption of SPM and TYL on $\mathrm{TiO}_{2}$-coated paper was facilitated by electrostatic attraction between the negatively charged photocatalyst surface and molecules cations. On the other side, at $\mathrm{pH}>\mathrm{pKa}$, the decrease in the degradation rate $(\mathrm{SPM} \sim 7 \%$ and TYL 44\%) could be attributed to the electrostatic repulsion due to the negative charge of ionized molecules (deprotonation). In addition, $\mathrm{OH}^{\bullet}$ radicals may be scavenged (Sakkas et al., 2007) and do not have the opportunity to react with pollutant molecules. The same tendency concerning $\mathrm{pH}$ influence has been reported by several authors (Haque and Muneer, 2007; Gad-Allah et al., 2011).

Consequently, acidic $\mathrm{pH}$ was more favorable for the photocatalytic degradation of SPM and TYL using CTCPP due to the higher adsorption of antibiotic molecules on $\mathrm{TiO}_{2}$-coated paper. A natural $\mathrm{pH} \sim 6$ seems to be the optimum for the degradation of both macrolides molecules.

\section{Effect of initial concentration and application of L-H model}

The effect of initial substrate concentration on the photocatalytic degradation efficiency was investigated in the range of $10-80 \mathrm{mg} \mathrm{L}^{-1}$, at a constant flow rate of $0.35 \mathrm{~L} \mathrm{~min}^{-1}$ and natural $\mathrm{pH}$. The removal rate of SPM and TYL decreases respectively from $90.8 \%$ and $83.6 \%$ to $65.5 \%$ and $41 \%$ after $300 \mathrm{~min}$ of reaction when increasing the initial concentration from 10 to $80 \mathrm{mg} \mathrm{L}^{-1}$ (Figure 3). As expected, a maximum degradation was observed at low concentrations in pollutant $\left(10\right.$ and $\left.20 \mathrm{mg} \mathrm{L}^{-1}\right)$ and the rate constant decreased with increasing initial concentration. This result can be explained by adsorption/desorption competition between the macrolide molecules and the degradation of intermediates, which may be predominant at high concentrations. In addition, since the amount of photocatalyst and the light intensity are constant in the reactor, the photogenerated oxidative species (primary $\mathrm{OH}^{\bullet}$ ) remain theoretically invariant.

Therefore, although initial macrolide concentration increases and adsorbed amount of macrolide on active surface of photocatalyst enhances, the degradation rate decreases due to a lower $\mathrm{OH}^{*} /$ pollutant ratio. In addition, the reduction of light penetration due to the increasing of initial concentration leads to less reactive sites creation (Merabet et al., 2009; Li et al., 2015).

Numerous investigations have demonstrated that heterogeneous photocatalysis of organic substrates could be described by L-H kinetic model (Yang et al., 2008; Merabet et al., 2009; Gad-Allah et al., 2010; Laoufi et al., 2013). This kinetic model is commonly used to rationalize the mechanisms of reactions occurring on solid surfaces (Kumar et al., 2008). If we note $\mathrm{r}_{0}\left(\mathrm{mg} \mathrm{L}^{-1} \mathrm{~min}^{-1}\right)$ the degradation rate, $\mathrm{L}-\mathrm{H}$ model can be expressed as follows: 


$$
r_{0}=-\frac{d C_{0}}{d t}=\frac{K_{L} k_{L H} C_{0}}{1+K_{L} C_{0}}
$$

where $\mathrm{k}_{\mathrm{L}-\mathrm{H}}\left(\mathrm{mg}^{-1} \mathrm{~L}\right.$ min) refers to apparent $\mathrm{L}-\mathrm{H}$ rate constant and $\mathrm{K}_{\mathrm{L}}\left(\mathrm{L} \mathrm{mg}^{-1}\right)$ to the adsorption/desorption equilibrium constant. The linearization form of $\mathrm{L}-\mathrm{H}$ model leads to:

$$
\frac{1}{r_{0}}=\frac{1}{k_{L H} K_{L}} \cdot \frac{1}{C_{0}}+\frac{1}{k_{L H}}
$$

The values of $\mathrm{k}_{\mathrm{LH}}$ and $\mathrm{K}_{\mathrm{L}}$ constants were determined by linear regression of the plot $1 / \mathrm{r}_{\mathrm{o}}$ versus $1 / \mathrm{C}_{\mathrm{o}}$ (Figure 4$)$. The obtained values for $\mathrm{SPM}\left(\mathrm{k}_{\mathrm{LH}}=1.413 \mathrm{mg}^{-1} \mathrm{~L} \min , \mathrm{K}_{\mathrm{L}}=0.0037 \mathrm{~L}\right.$ $\left.\mathrm{mg}^{-1}\right)$ and TYL $\left(\mathrm{k}_{\mathrm{LH}}=0.5128 \mathrm{mg}^{-1} \mathrm{~L} \min , \mathrm{K}_{\mathrm{L}}=0.0136 \mathrm{~L} \mathrm{mg}^{-1}\right)$ were of the same order of magnitude than those reported in the literature for the antibiotics photodegradation (GadAllah et al., 2011; Dimitrakopoulou et al., 2012). It also appears that SPM degraded faster than TYL and the kinetic reaction step is considered to be the limited step.

These results confirm that $\mathrm{L}-\mathrm{H}$ model is suitable to describe the kinetic of SPM and TYL degradation using the CTCPP under the investigated conditions.

\section{Effect of flow rate}

The effect of flow rate on the degradation efficiency of both SPM and TYL was also studied. The operating values of investigated flow rates were in the range of $0.2-0.55 \mathrm{~L} \mathrm{~min}^{-1}$. The obtained profiles are summarized in Figure 5. After 300 min of reaction, the maximum $k_{a p}$ value $\left(0.0086 \mathrm{~min}^{-1}\right.$ for SPM and $0.0066 \mathrm{~min}^{-1}$ for TYL) and maximum removal efficiency $(\sim 80 \%)$ were achieved under $0.35 \mathrm{~L} \mathrm{~min}^{-1}$ optimum flow rate.

In the case of any continuous-flow photoreactor, the flow rate is considered as an important factor that affects photocatalytic reaction by changing the convective mass transfer and residence time in the reactor. Convective mass transfer is the more predominant factor that influences the photocatalytic reaction at low flow rate, while residence time is the primary limiting factor at high flow rate (Li et al., 2014).

Up to $0.35 \mathrm{~L} \mathrm{~min}^{-1}$, the enhancement of degradation efficiency with increasing flow rate indicates that convective mass transfer is the primary limiting factor and then, the diffusion between macrolide and photocatalyst is improved in both SPM and TYL degradation.

Beyond $0.35 \mathrm{~L} \mathrm{~min}^{-1}$, increasing flow rate leads to lowering the degradation efficiency. In this work, residence time should not play a significant role as we are in the case of circulating reactor. May be hydrodynamic flow regime can play a role. This aspect will be investigated later in the RTD study.

\section{Mineralization of target macrolides}

In this work, the extent of the antibiotics mineralization was determined by measuring the total organic carbon in the reaction system. Figure 6 presents the comparison between percentages of TOC removal for four different initial pollutant concentrations after $300 \mathrm{~min}$ of irradiation. We note that for lower concentrations, over than half of the initial SPM content and about $35 \%$ for TYL have been mineralized after a treatment time of $5 \mathrm{~h}$. At that time, both antibiotics were almost at their maximum abatement.

Further, the obtained values lead us to confirm the presence of organic intermediates generated during the photocatalytic process which compete for adsorption and subsequent photocatalytic degradation. However, the complete mineralization was not achieved for the 
considered experimental time duration. It could be supposed that by increasing the irradiation time, most of the reaction by-products would be transformed into inorganic substances such as $\mathrm{CO}_{2}$ and $\mathrm{H}_{2} \mathrm{O}$.

In addition, both target pollutants have a complex molecular structure which leads to hard mineralization. The difference between mineralization efficiencies of SPM and TYL strongly depend on their molecular structure. Indeed, SPM which has a relatively lower molecular weight than TYL achieved the maximum mineralization (55\%).

\section{RTD studies and characterization of flow pattern}

In order to well analyze the effect of flow rate on removal efficiency and characterize the liquid flow pattern, RTD studies were carried out for forth-selected values of flow rate $(0.25$, $0.35,0.45,0.55 \mathrm{~L} \mathrm{~min}^{-1}$ ).

The residence time distribution was evaluated using $\mathrm{E}(\mathrm{t})$ variation with time at the exit of reactor. In this work, $\mathrm{KCl}$ was chosen as a tracer (Gholami et al., 2012).

In order to investigate the effect of flow rate on the RTD performance more closely, RTD curves are plotted versus time for each flow rate as shown in Figure 7. E(t) function is expressed as follows:

$$
E(t)=\frac{C_{i}}{\boldsymbol{f}_{0}^{\infty 0} C d t}
$$

where $\mathrm{C}_{\mathrm{i}}$ is tracer concentration at the exit time $\mathrm{t}$.

As a consequence, the mean residence time $\left(\bar{t}_{m}\right)$, the variance of the residence time $\left(\sigma^{2}\right)$ and the dimensionless variance $\left(\sigma_{\bar{D}}^{\tilde{D}}\right)$ are calculated from the following equations and the results are summarized in table 2:

$$
\begin{aligned}
& \bar{t}_{m}=\int_{0}^{\infty} t E d t \cong \frac{\Sigma t_{i} C_{i} \Delta t_{i}}{\Sigma C_{i} \Delta t_{i}} \\
& \sigma^{z}=\int_{0}^{\infty}\left(t-\bar{t}_{m}\right)^{2} E d t=\frac{\Sigma\left(t-\bar{t}_{m}\right)^{2} C_{i} \Delta t_{i}}{\Sigma C_{i} \Delta t_{i}} \\
& \sigma_{D}^{z}=\left(\frac{\sigma}{\bar{t}_{m}}\right)^{2}
\end{aligned}
$$

It could be observed that the increase in flow rate results in a decrease of $\bar{t}_{m}$ in the reactor. Generally, $\bar{t}_{m}$ is the most common parameter of concern and is an indicative of the average transient time of processing material. A lower value of $\bar{t}_{m}$ indicates higher mean velocity of the flowing material.

In addition, the RTD dimensionless variance $\left(\sigma_{D}^{z}\right)$ can be considered as a measure of the dispersion. A lower value of $\sigma_{\bar{D}}^{z}\left(\sigma_{\bar{D}}^{2} \rightarrow \mathbf{0}\right)$ indicates lesser dispersion and the flow approaches to near plug flow. On the other hand, a higher value of $\sigma_{D}^{\mathbf{z}}$ indicates higher dispersion and the flow approaches to perfectly mixed flow (Khataee et al., 2010).

In order to characterize the RTD quantitatively in the photoreactor, the single parameter model was chosen in this work: the tanks-in-series model, where the real circulation loop is 
replaced by a series of consecutive, equal volume of ideally stirred tank reactors, resulting in the same longitudinal mixing effect. The degree of mixing is characterized by the number of equivalent stirred tank reactors $\left(\mathrm{N}_{\mathrm{eq}}\right)$ and could be calculated according to Eq. (8).

$$
\mathrm{N}_{\mathrm{eq}}=1 / \sigma_{D}^{2}
$$

We note that experimental reactor can be represented by a series of 3 to 5 mixed reactors. Increasing flow rate within the studied range doesn't considerably affect the flow regime into the reactor. It appears that $0.25 \mathrm{~L} \mathrm{~min}^{-1}$ flow rate is the optimum value corresponding to lowest dispersion. The flow regime is close to plug flow.

Thus, considering the maximum removal efficiency of both SPM and TYL $(\sim 80 \%)$, and also the determined flow characteristics and RTD studies, the value of $0.35 \mathrm{~L} \mathrm{~min}^{-1}$ appears to be the optimum flow rate in the case of the studied CTCPP.

This good performance of our experimental reactor can be due to the hydrodynamic behavior of the process. Indeed, RTD experiments show that experimental reactor can be represented by at least 4 stirred reactors in series. For a first order reaction, the presence of stirred reactor in series leads to better degradation rate (Fogler, 1998).

\section{Evaluation of electrical energy per order (EE/O)}

The electrical energy consumption has been proposed as a figure-of-merit for comparing the cost of each AOPs technology. Bolton et al. (2001) defined the electric energy per order $(\mathrm{EE} / \mathrm{O})$ to use at the first-order kinetic regime at the low pollutant concentrations. It is defined as the number of kilowatt hours of electrical energy required to reduce the pollutant concentration by 1 order of magnitude per $1 \mathrm{~m}^{3}$ of contaminated water. Assuming first-order kinetics, EE/O ( $\mathrm{kWh} \mathrm{m}^{-3}$ order $\left.^{-1}\right)$ can be calculated from the following equation for a batch reactor:

$$
\frac{\mathrm{EE}}{\mathbf{0}}=\frac{P \times t \times 1000}{V \times 60 \times \log \left(C_{i} / C_{f}\right)}
$$

where $\mathrm{P}(\mathrm{kW})$ is the power of the AOP system, $\mathrm{t}(\mathrm{min})$ the irradiation time, $\mathrm{V}(\mathrm{L})$ the treated solution volume, $\mathrm{C}_{\mathrm{i}}$ and $\mathrm{C}_{\mathrm{f}}$ are the initial and final pollutant concentrations, respectively.

The calculated EE/O values for SPM and TYL photodegradation in the optimal conditions $\left(\mathrm{C}_{0}\right.$ $=10 \mathrm{mg} \mathrm{L}^{-1}$, Flow rate $=0.35 \mathrm{~L} \mathrm{~min}^{-1}$, natural $\mathrm{pH}$ ) were 20.09 and $26.18 \mathrm{kWh} \mathrm{m}^{-3}$ order $^{-1}$ respectively. These values showed that the studied system offered the best energetic efficiency compared to those reported in other studies (Table 3).

The obtained data clearly showed that, at optimal operating conditions, the studied reactor presents a better degradation efficiency and energy consumption.

\section{Study of the stability of the photocatalyst media}

For ROPs treatment in water, repetitive operation performance is one of the most important parameters for practical application of any developed photocatalytic reactor, to reduce the cost implications (Li et al., 2014). A catalyst reuse study was conducted to determine the stability 
of $\mathrm{TiO}_{2}$-coated paper over nine catalytic cycles. Experiments were carried out for TYL over 300 min in each cycle. As shown in Figure 8, about $80 \%$ of TYL was decomposed after 9 cycles of catalyst use. A low degradation removal was recorded in the first uses of the photocatalyst $\left(46.7 \%\right.$ and $62.3 \%$ for the $1^{\text {st }}$ and $2^{\text {nd }}$ cycle respectively). This lack in the degradation efficiency is probably due to the presence of impurities on the surface of the $\mathrm{TiO}_{2}$-coated paper which disappear with its reuse. Furthermore, it can be seen that the photocatalytic activity of the catalyst increases (up to 77.8\%) after the third catalytic cycle. Even after nine cycles, the immobilized photocatalyst preserves its performance and the apparent rate constant remains high (Figure 8).

These results demonstrate that the used photocatalyst have high catalytic stability which leads to the good reproducibility of the reactor for macrolides degradation. The high repetitive operation performance, as well as the high photocatalytic efficiency and the low energy consumption, makes the CTCPP a promising alternative for the degradation of macrolides in water.

\section{CONCLUSIONS}

In this work, the degradation efficiency of SPM and TYL in a circulating $\mathrm{TiO}_{2}$-coated paper photoreactor (CTCPP) was investigated under some operating conditions such as low power UV-lamp, immobilized catalyst, different $\mathrm{pH}$, initial pollutant concentration and flow rate. The developed photoreactor system shows high degradation efficiency, low energy consumption and good repetitive operation performance for photocatalytic removal of macrolide antibiotics in water. The conclusions based on the experimental results can be summarized as follows:

1. The optimal determined conditions were an initial pollutant concentration lower than $20 \mathrm{mg} \mathrm{L}^{-1}, 0.35 \mathrm{~L} \mathrm{~min}^{-1}$ flow rate and natural $\mathrm{pH}$ solution. Application of L-H model revealed that photocatalytic degradation is reaction step limited.

2. The mineralization of both antibiotics was not complete even at high catalyst photoactivity. The difference between mineralization efficiencies of antibiotics strongly depends on their molecular structure. Further studies on the determination of photodegradation pathway of both SPM and TYL and their formed by-products are under progress.

3. RTD analysis showed that experimental reactor can be represented as a 4 tanks in series. This leads to better degradation performance and energy consumption.

4. The stability of the photocatalyst media has been attested. Nine repetitive catalytic cycles have not altered the efficiency of the photocatalyst.

\section{References}

Aguedach, A., Brosillon, S., Morvan, J., Lhadi, E. 2005 Photocatalytic degradation of azodyes Reactive Black 5 and Reactive Yellow 145 in water over a newly deposited titanium dioxide. Applied Catalysis, B : Environmental, 57(1), 55-62.

Bolton, J. R., Bircher, K. G., Tumas, W., \& Tolman, C. A. 2001 Figures-of-merit for the technical development and application of advanced oxidation technologies for both electric-and solar-driven systems (IUPAC Technical Report). Pure and Applied Chemistry, 73(4), 627-637. 
Civitareale, C., Fiori, M., Ballerini, A., \& Brambilla, G. 2004 Identification and quantification method of spiramycin and tylosin in feedingstuffs with HPLC-UV/DAD at 1ppm level. Journal of Pharmaceutical and Biomedical Analysis,36(2), 317-325.

Dimitrakopoulou, D., Rethemiotaki, I., Frontistis, Z., Xekoukoulotakis, N. P., Venieri, D., \& Mantzavinos, D. 2012 Degradation, mineralization and antibiotic inactivation of amoxicillin by UV-A/TiO 2 photocatalysis. Journal of Environmental Management, 98, 168-174.

Doll, T. E., \& Frimmel, F. H. 2005 Removal of selected persistent organic pollutants by heterogeneous photocatalysis in water. Catalysis Today, 101(3), 195-202.

Elanco, C. 1982 Tylan injection veterinarian's technical handbook. Elanco Products company, Indianapolis, IN.

Fogler, S. 1998 Chemical Reactions Engineering. Prentice Hall, New York City.

Gad-Allah, T. A., Ali, M. E., \& Badawy, M. I. 2011 Photocatalytic oxidation of ciprofloxacin under simulated sunlight. Journal of Hazardous Materials,186(1), 751-755.

Gaya, U. I., \& Abdullah, A. H. 2008 Heterogeneous photocatalytic degradation of organic contaminants over titanium dioxide: a review of fundamentals, progress and problems. Journal of Photochemistry and Photobiology C: Photochemistry Reviews, 9(1), 1-12.

Gholami, R. M., Mousavi, S. M., \& Borghei, S. M. 2012 Process optimization and modeling of heavy metals extraction from a molybdenum rich spent catalyst by Aspergillus niger using response surface methodology. Journal of Industrial and Engineering Chemistry, 18(1), 218-224.

Ghafoori, S., Mehrvar, M., \& Chan, P. K. 2014 Photoreactor scale-up for degradation of aqueous poly (vinyl alcohol) using $\mathrm{UV} / \mathrm{H}_{2} \mathrm{O}_{2}$ process. Chemical Engineering Journal, $245,133-142$.

Heberer,T. 2002 Occurrence, fate, and removal of pharmaceutical residues in the aquatic environment: a review of recent research data, Toxicology Letters, 131(1), 5-17.

Haque, M. M., \& Muneer, M. 2007 Photodegradation of norfloxacin in aqueous suspensions of titanium dioxide. Journal of Hazardous Materials, 145(1), 51-57.

Huang, C. H., Renew, J. E., Pinkston, K., \& Sedlak, D. L. 2001 Occurrence and fate of antibiotic compounds in municipal wastewater and animal waste. Proceedings of the Water Environment Federation, 11, 686-697.

Khataee, A. R., Fathinia, M., \& Aber, S. 2010 Kinetic modeling of liquid phase photocatalysis on supported $\mathrm{TiO}_{2}$ nanoparticles in a rectangular flat-plate photoreactor. Industrial \& Engineering Chemistry Research, 49(24), 12358-12364.

Kumar, K. V., Porkodi, K., \& Rocha, F. 2008 Langmuir-Hinshelwood kinetics-a theoretical study. Catalysis Communications, 9(1), 82-84.

Kümmerer, K., Al-Ahmad, A., \& Mersch-Sundermann, V. 2000 Biodegradability of some antibiotics, elimination of the genotoxicity and affection of wastewater bacteria in a simple test. Chemosphere, 40(7), 701-710.

Laoufi, N. A., Hout, S., Tassalit, D., Ounnar, A., Djouadi, A., Chekir, N., \& Bentahar, F. 2013 Removal of a persistent pharmaceutical micropollutant by $\mathrm{UV} / \mathrm{TiO}_{2}$ process using an immobilized titanium dioxide catalyst: Parametric study. Chemical Engineering, 32, 1951-1958.

Li, D., Zhu, Q., Han, C., Yang, Y., Jiang, W., \& Zhang, Z. 2015 Photocatalytic degradation of recalcitrant organic pollutants in water using a novel cylindrical multi-column photoreactor packed with $\mathrm{TiO}_{2}$-coated silica gel beads. Journal of Hazardous Materials, 285, 398-408.

Li, D., Zheng, H., Wang, Q., Wang, X., Jiang, W., Zhang, Z., \& Yang, Y. 2014 A novel double-cylindrical-shell photoreactor immobilized with monolayer $\mathrm{TiO}_{2}$-coated silica 
gel beads for photocatalytic degradation of Rhodamine B and Methyl Orange in aqueous solution. Separation and Purification Technology, 123, 130-138.

Lhomme, L., Brosillon, S., \& Wolbert, D. 2008 Photocatalytic degradation of pesticides in pure water and a commercial agricultural solution on $\mathrm{TiO}_{2}$ coated media. Chemosphere, 70(3), 381-386.

Merabet, S., Bouzaza, A., \& Wolbert, D. 2009 Photocatalytic degradation of indole in a circulating upflow reactor by $\mathrm{UV} / \mathrm{TiO}_{2}$ process-influence of some operating parameters. Journal of Hazardous Materials, 166(2), 1244-1249.

Michael, I., Rizzo, L., McArdell, C. S., Manaia, C. M., Merlin, C., Schwartz, T., Dagot, C. \& Fatta-Kassinos, D. 2013 Urban wastewater treatment plants as hotspots for the release of antibiotics in the environment: a review. Water Research, 47(3), 957-995.

Paz, Y. In: De Lasa, H., \& Serrano-Rosales, B. 2009 Advances in Chemical Engineering: Photocatalytic Technologies, Academic Press, pp. 289-336.

Parsons, S. 2004 Advanced oxidation processes for water and wastewater treatment. IWA publishing, Cornwall, UK.

Petit, N., Bouzaza, A., Wolbert, D., Petit, P., \& Dussaud, J. 2007 Photocatalytic degradation of gaseous perchloroethylene in continuous flow reactors: Rate enhancement by chlorine radicals. Catalysis Today, 124(3), 266-272.

Sahle-Demessie, E., Bekele, S., \& Pillai, U. R. 2003 Residence time distribution of fluids in stirred annular photoreactor. Catalysis Today, 88(1), 61-72.

Sakkas, V. A., Calza, P., Medana, C., Villioti, A. E., Baiocchi, C., Pelizzetti, E., \& Albanis, T. 2007 Heterogeneous photocatalytic degradation of the pharmaceutical agent salbutamol in aqueous titanium dioxide suspensions. Applied Catalysis B: Environmental, 77(1), 135-144.

Santaballa, J. A., Maskill, H. \& López, M. C. 2006. Investigating Organic Reaction Mechanisms. Blackwell Publishing Ltd., Oxford.

Schiavello, M. 1988 Photocatalysis and environment. Kluwer Academic Publishers, Dordrecht.

Yang, L., Liya, E. Y., \& Ray, M. B. 2008 Degradation of paracetamol in aqueous solutions by $\mathrm{TiO}_{2}$ photocatalysis. Water Research, 42(13), 3480-3488. 
Figures captions

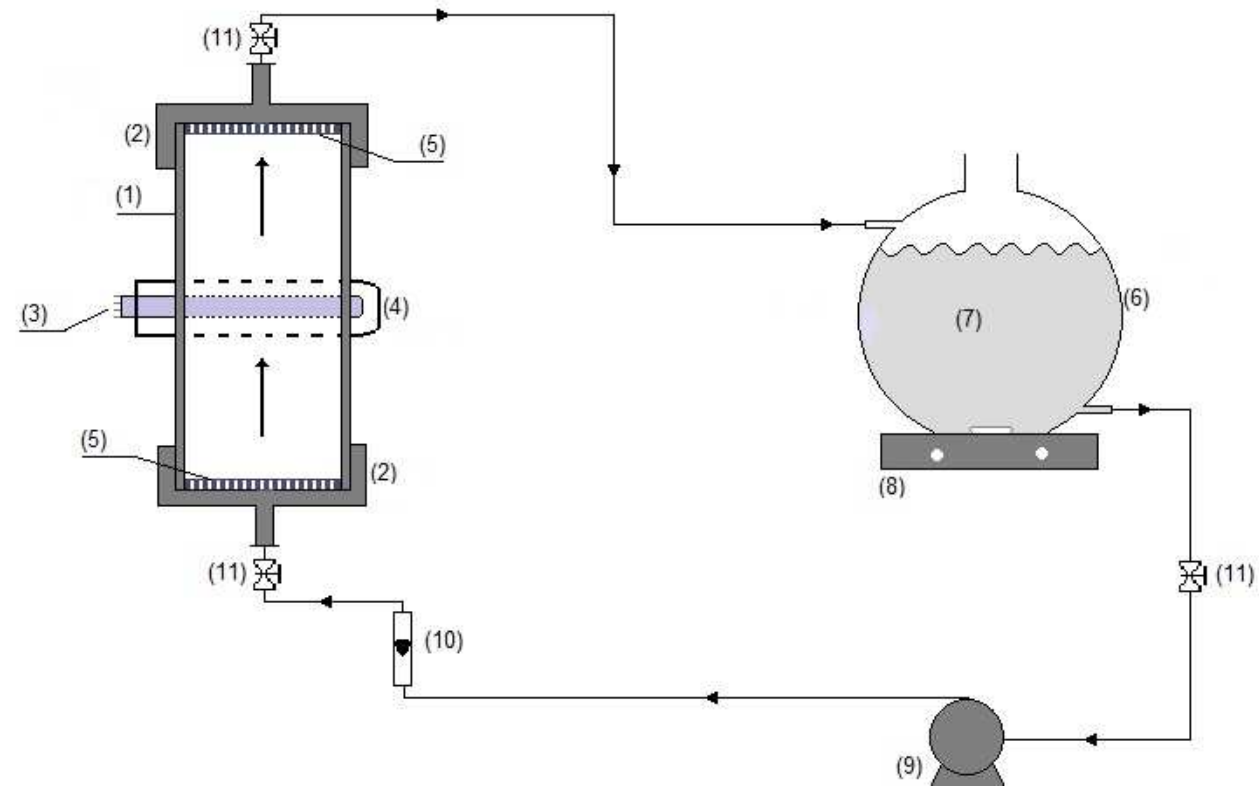

Figure 1. Experimental set-up: (1) column; (2) support; (3) UV lamp; (4) pyrex tube; (5) catalyst paper; (6) tank; (7) solution; (8) magnetic stirrer; (9) peristaltic pump; (10) flowmeter; (11) valve. 

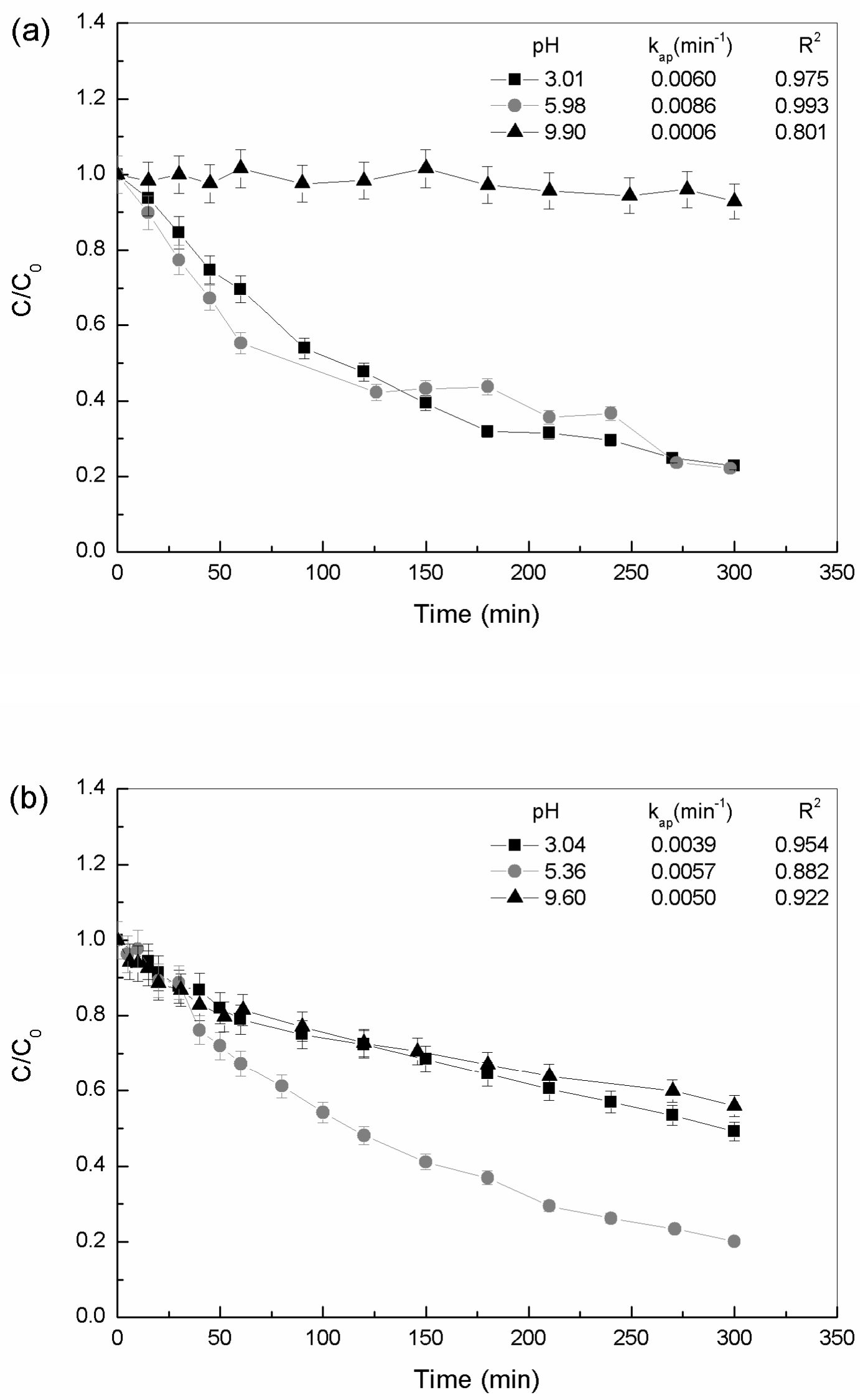
Figure 2. Effect of $\mathrm{pH}$ on the photocatalytic degradation: (a) SPM ; (b) TYL, $\left(\mathrm{C}_{0}=10 \mathrm{mg} \mathrm{L}^{-1}\right.$, Flow rate: $0.35 \mathrm{~L} \mathrm{~min}^{-1}$ ).

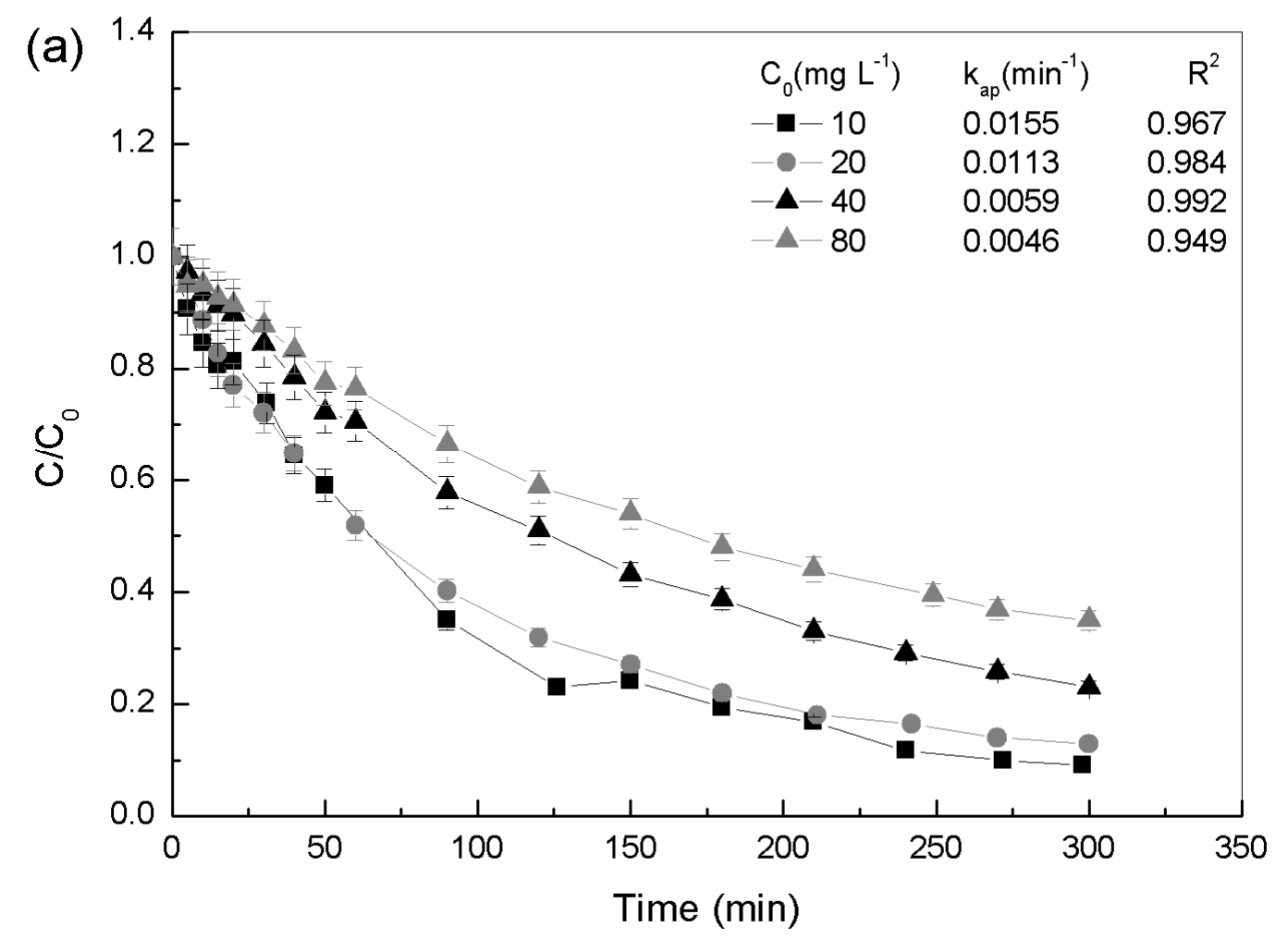




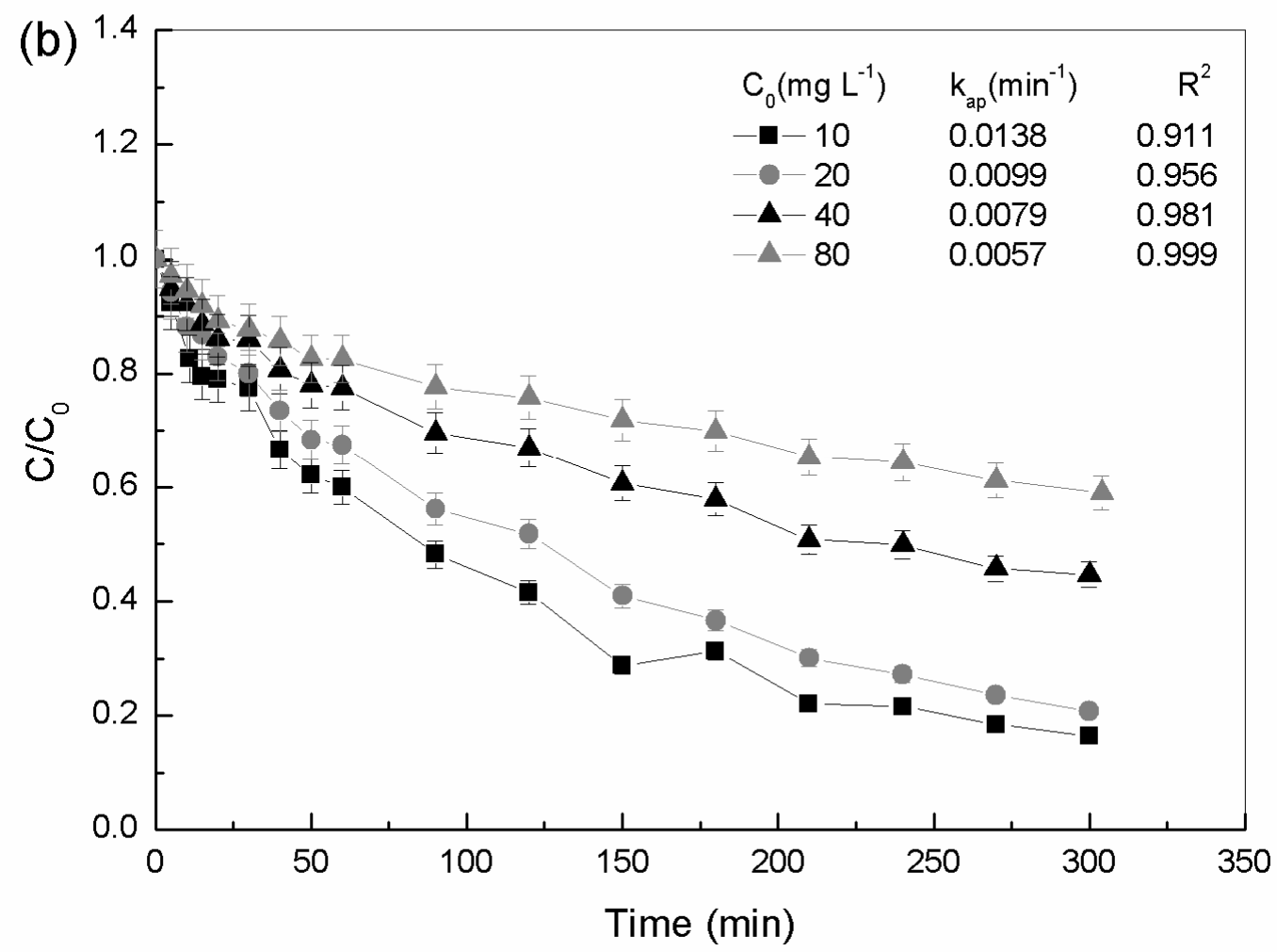

Figure 3. Effect of initial concentration on the photocatalytic degradation: (a) SPM ; (b) TYL, (natural $\mathrm{pH}$, Flow rate : $0.35 \mathrm{~L} \mathrm{~min}^{-1}$ ). 


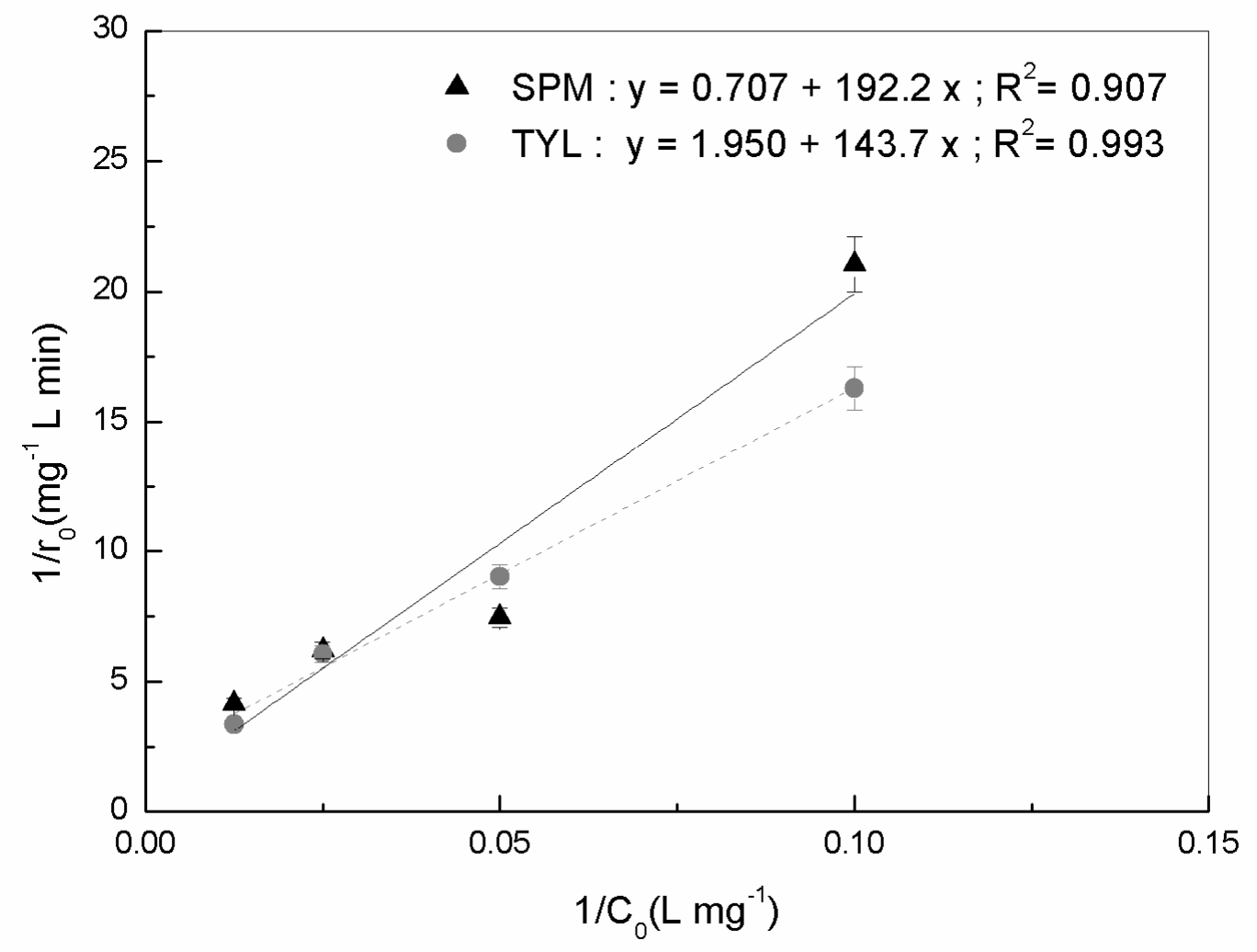

Figure 4. Determination of L-H model constants for SPM and TYL degradation. 

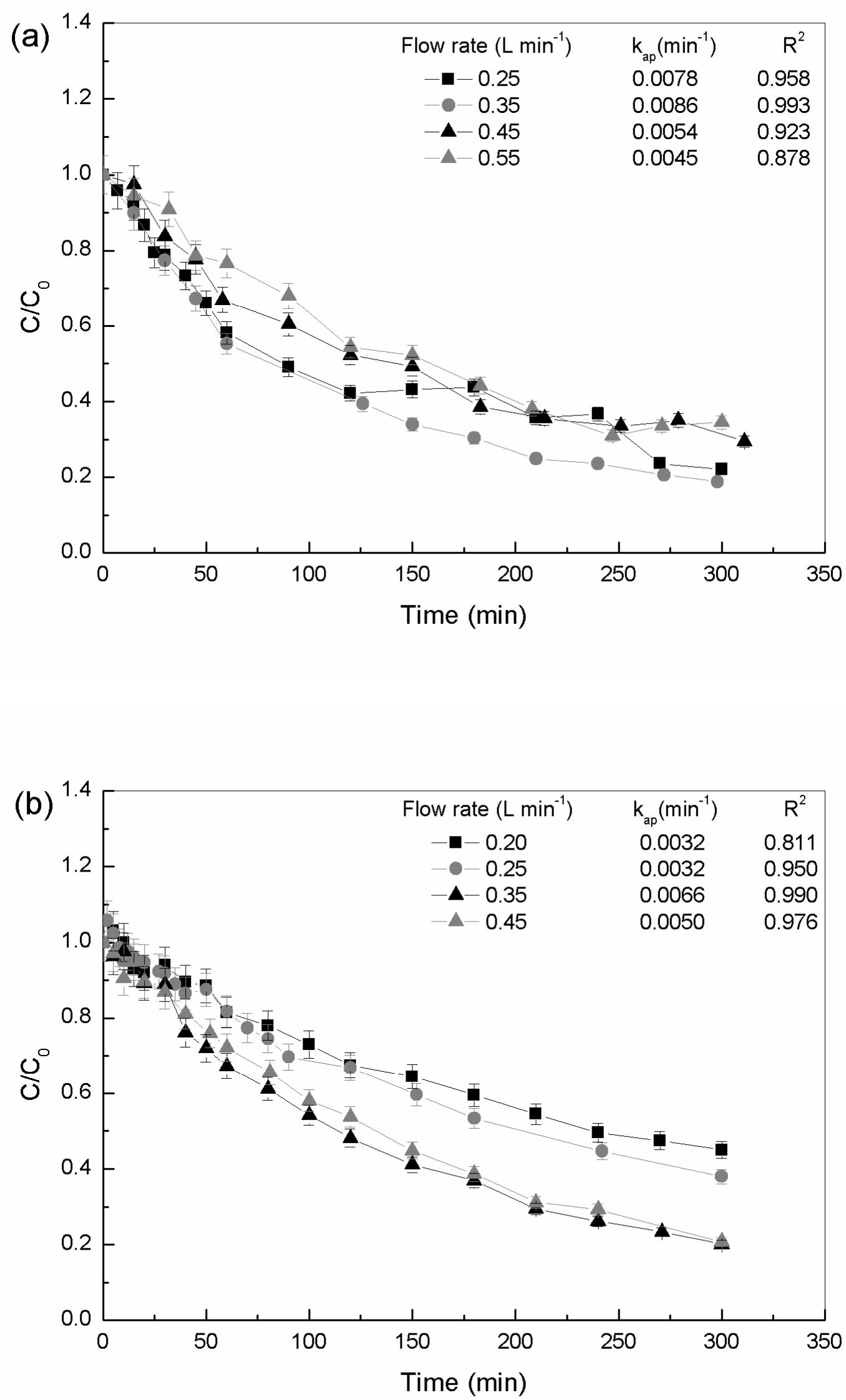
Figure 5. Effect of flow rate on the photocatalytic degradation: (a) SPM ; (b) TYL, (natural $\left.\mathrm{pH}, \mathrm{C}_{0}=10 \mathrm{mg} \mathrm{L}^{-1}\right)$.

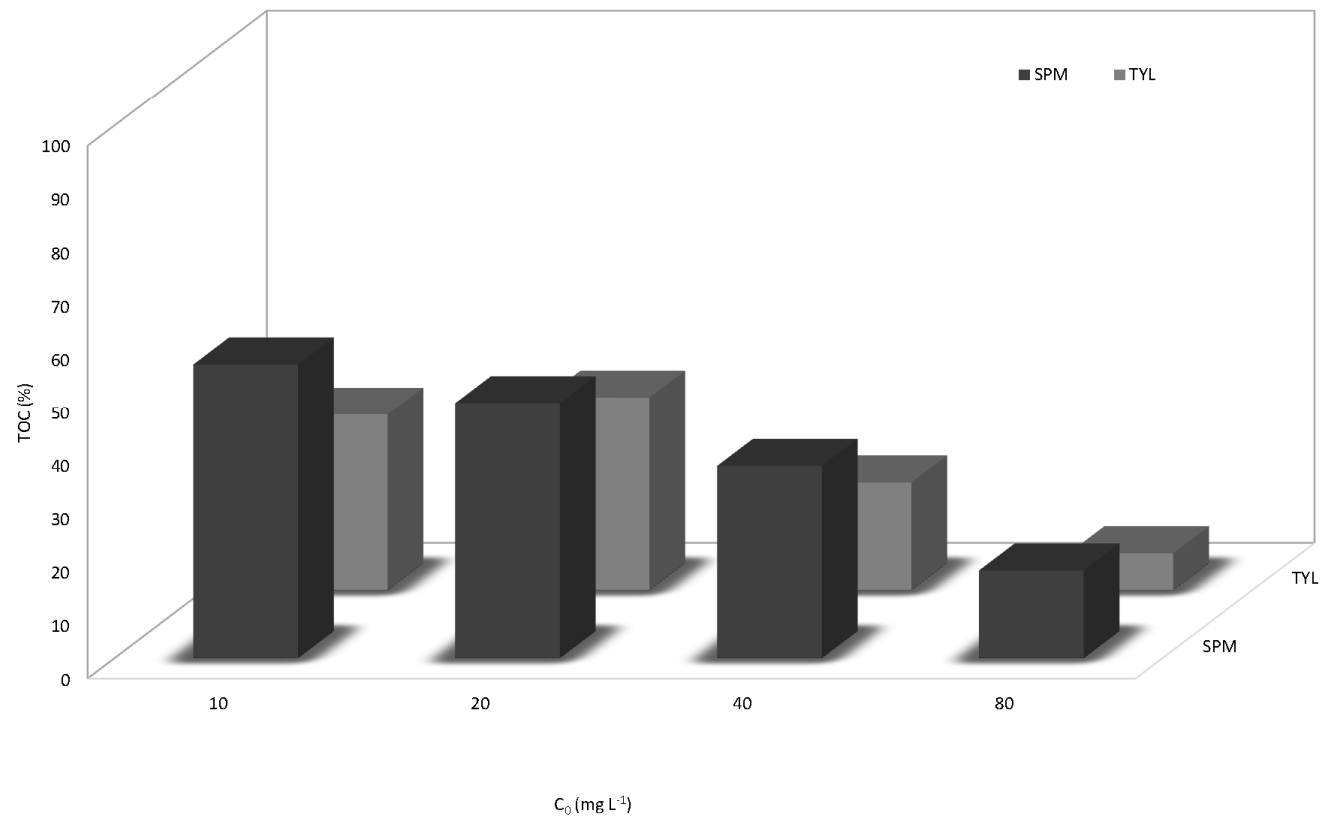

Figure 6. Mineralization efficiency of macrolides versus initial pollutant concentration. 
(a)
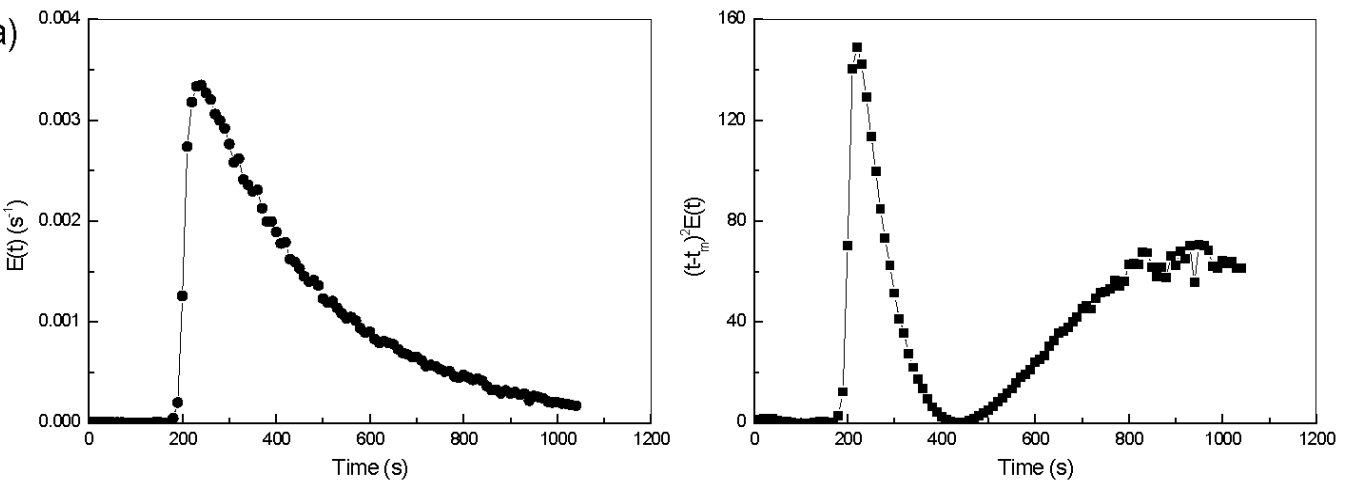

(b)
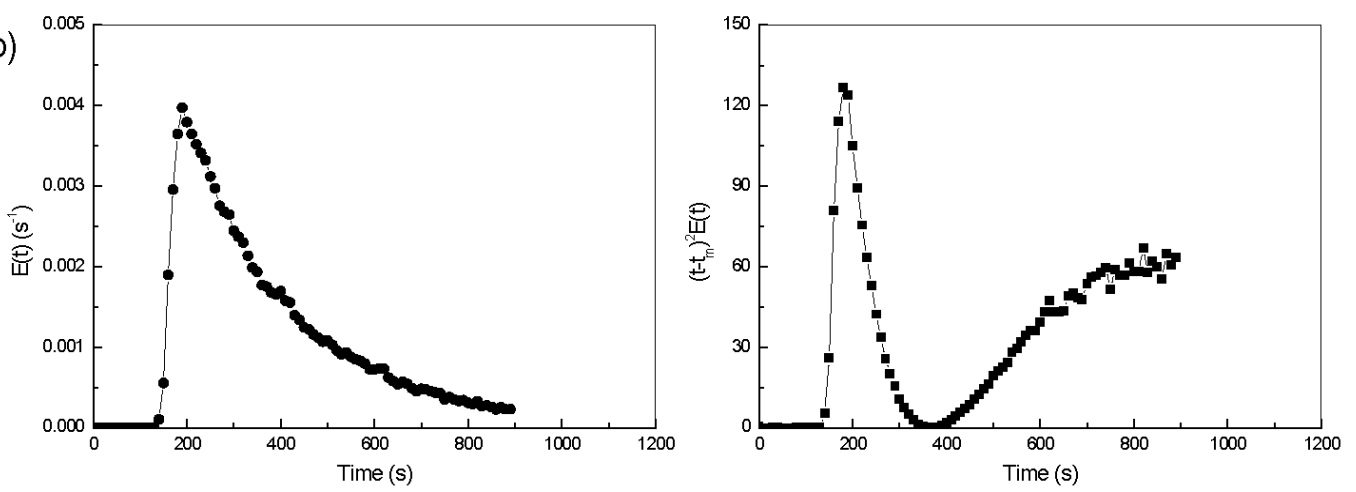

(c)
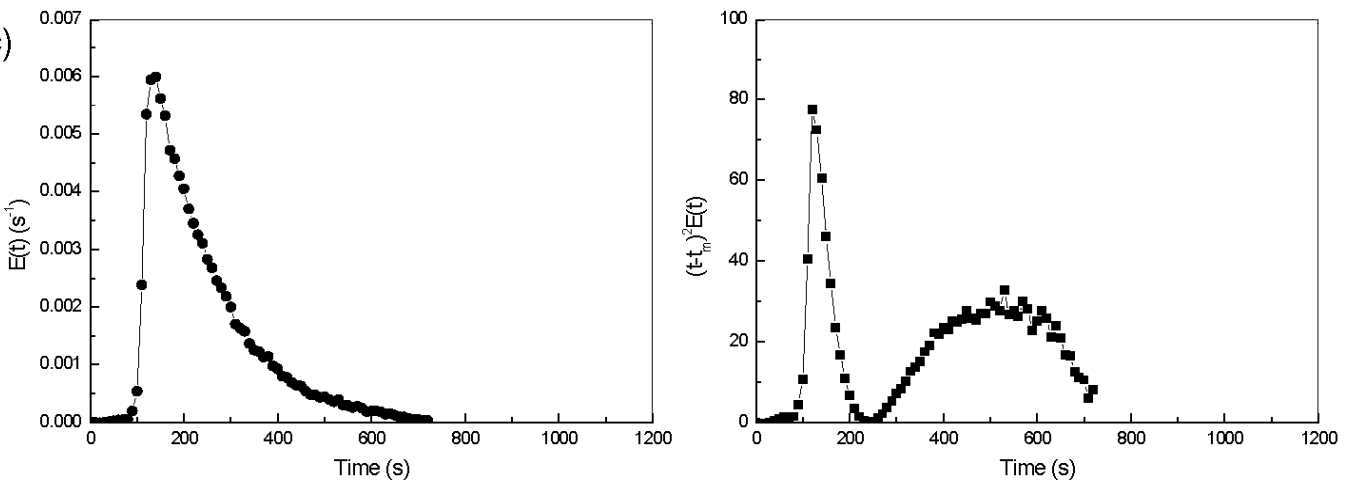

(d)
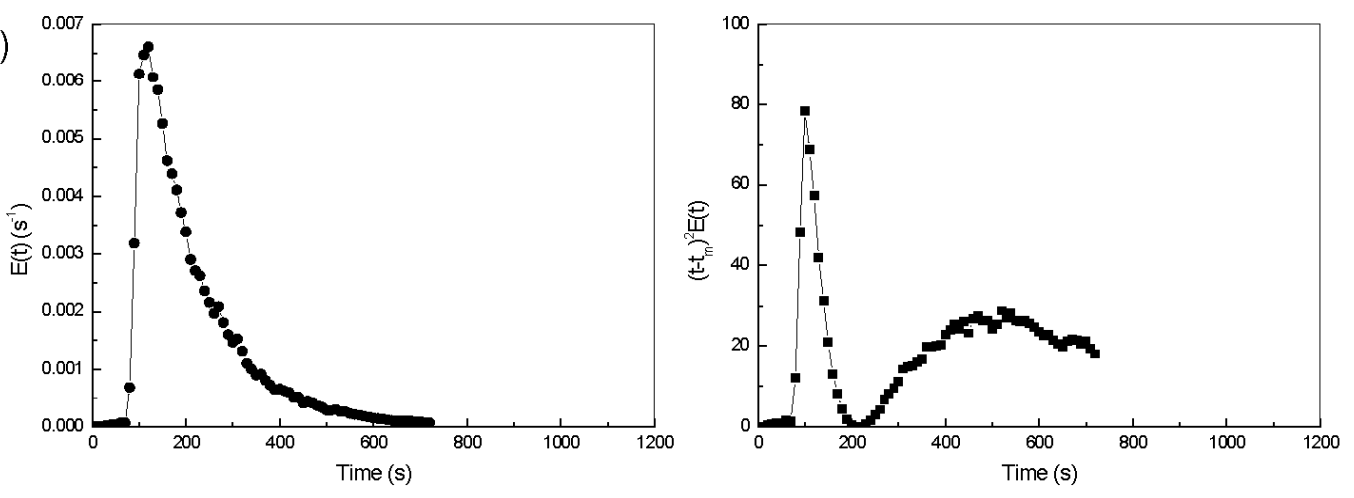

Figure 7. Typical RTD curves at different flow rates. (a) 0.25; (b) 0.35 ; (c) 0.45 and (d) 0.55 $\mathrm{L} \min ^{-1}$ 

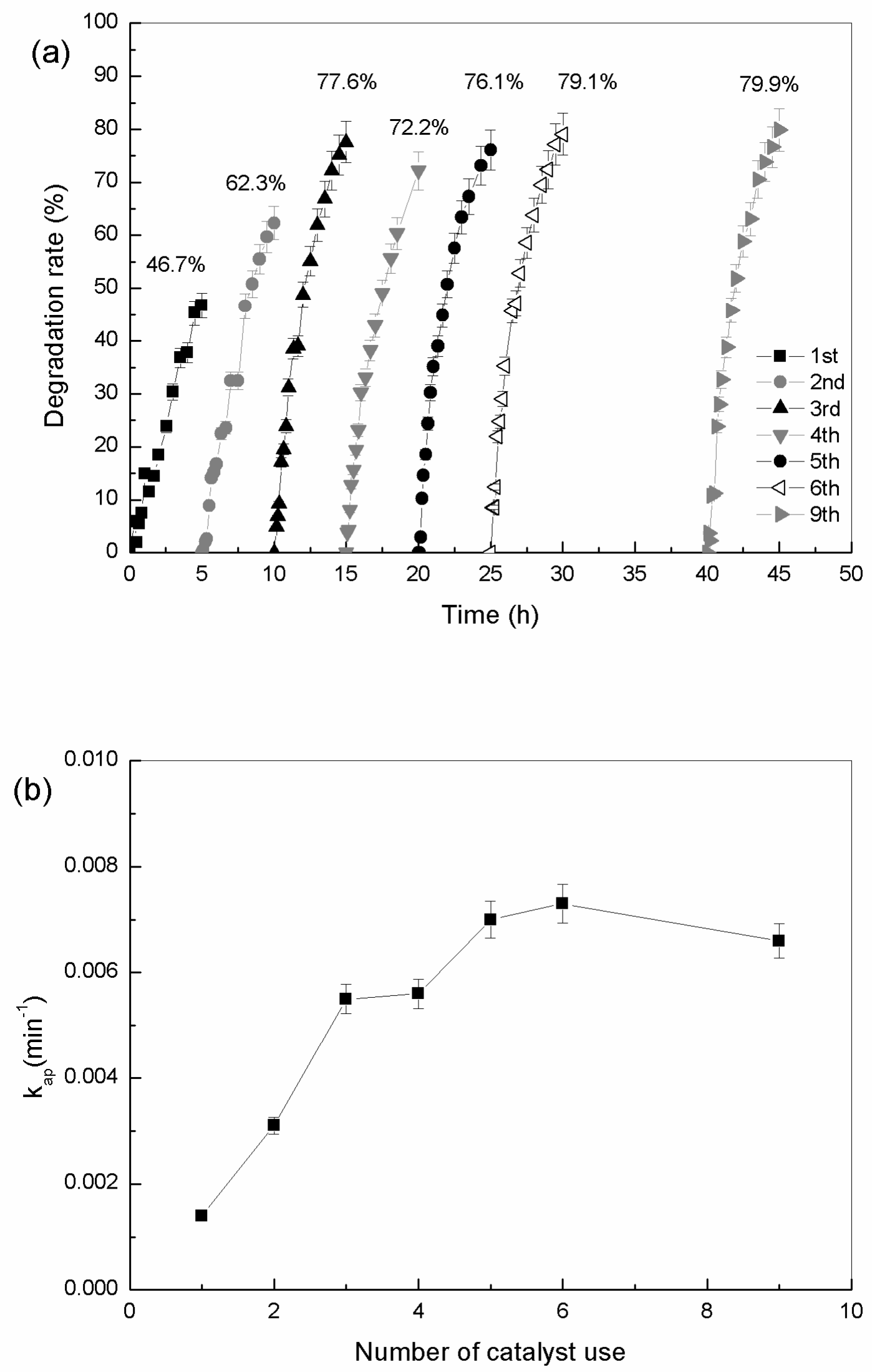
Figure 8. Reuse of the $\mathrm{TiO}_{2}$-coated paper: (a) Removal rate evolution (b) Kinetic constant evolution, $\left(\mathrm{C}_{0}=10 \mathrm{mg} \mathrm{L}^{-1}\right.$, natural $\mathrm{pH}$, flow rate $\left.=0.25 \mathrm{~L} \mathrm{~min}^{-1}\right)$.

\section{Tables}

Table 1. Physicochemical properties and characterization of SPM and TYL

\begin{tabular}{lll}
\hline Compound/group & Spiramycin/macrolide & Tylosin/macrolide \\
\hline Use & Antibacterial for human and & Antibacterial for veterinary medicine \\
veterinary medicine & \\
CAS number & $24916-50-5$ & $1401-69-0$ \\
$\begin{array}{l}\text { Formula } \\
\text { Structure }\end{array}$ & 843.1 & 916.1 \\
& &
\end{tabular}

Table 2. Characteristic parameters of flow regime

\begin{tabular}{llll}
\hline $\begin{array}{l}\text { Flow rate } \\
\left(\mathrm{L} \mathrm{min}^{-1}\right)\end{array}$ & & $\boldsymbol{\sigma}_{\mathrm{B}}^{\mathbf{2}}$ & \\
& & & \\
& $\bar{t}_{\mathrm{m}}$ & & \\
& & & \\
& & & \\
& $(\min )$ & & \\
& & & \\
\hline 0.25 & & & 4.89 \\
0.35 & 7.27 & 0.204 & 4.43 \\
0.45 & 6.11 & 0.225 & 4.33 \\
0.55 & 4.01 & 0.231 & 3.28 \\
\hline
\end{tabular}

Table 3. Electrical energy per order (EE/O) for some reported photoreactors in the case of pharmaceuticals photocatalytic degradation 


\begin{tabular}{|c|c|c|c|}
\hline Pollutant & Photoreactor & $\mathrm{EE} / \mathrm{O}\left(\mathrm{kWh} \mathrm{m}^{-3}\right)$ & Reference \\
\hline Paracetamol & $\begin{array}{l}\mathrm{TiO}_{2} \text { suspension } \\
\text { photoreactor }\end{array}$ & 560.76 & Yang et al., 2008 \\
\hline Tylosin & $\begin{array}{l}\mathrm{TiO}_{2} \text { suspension } \\
\text { photoreactor }\end{array}$ & 468.61 & Laoufi et al., 2013 \\
\hline Amoxicillin & $\begin{array}{l}\mathrm{TiO}_{2} \text {-coated beads } \\
\text { photoreactor }\end{array}$ & $1.97 \times 10^{5}$ & Li et al., 2015 \\
\hline
\end{tabular}

